\title{
Additive Effect on Lithium Silicate Pellets for Thermochemical Energy Storage
}

\author{
Hiroki TAKasu ${ }^{1}$, Takuya Ninei ${ }^{2}$, Seon Tae Kim ${ }^{1}$ and Yukitaka Kato ${ }^{1}$ \\ ${ }^{1}$ Zaboratory for Advanced Nuclear Energy, Institute of Innovative Research, Tokyo Institute of Technology, \\ 2-12-1-N-22 Ookayama, Meguro-ku, Tokyo 152-8550, Japan \\ ${ }^{2}$ Graduate Major in Nuclear Engineering, Tokyo Institute of Technology, 2-12-1-N-22 Ookayama, \\ Meguro-ku, Tokyo 152-8550, Japan
}

Keywords: Thermochemical Energy Storage, $\mathrm{CO}_{2}$ Absorption, Metal Oxides, Carbonate Salt

\begin{abstract}
The global increase in energy consumption has caused serious environmental problems, especially $\mathrm{CO}_{2}$ emissions. In general, $\mathrm{CO}_{2}$ is produced from the combustion and oxidation reactions at high temperature. The use of thermochemical energy storage is considered an appropriate approach to enhance the utilization of surplus or waste heat from high temperature industrial processes. So far, there are very few reports that have been published for high temperature thermochemical energy storage. In this study, high temperature thermochemical energy storage based on the lithium orthosilicate/carbon dioxide $\left(\mathrm{Li}_{4} \mathrm{SiO}_{4} / \mathrm{CO}_{2}\right)$ reaction was developed. A new candidate storage material was fabricated with four different concentrations of the potassium carbonate $\left(\mathrm{K}_{2} \mathrm{CO}_{3}\right)$ additive $(0,6,11,17$, and $33 \mathrm{~mol} \%)$, in the shape of pellets, from the point of energy density view. On the basis of the results of the carbonation and decarbonation experiments, the highest thermal output and storage densities were recorded for a pellet possessing a $11 \mathrm{~mol} \%$ concentration of the $\mathrm{K}_{2} \mathrm{CO}_{3}$ additive. Furthermore, this pellet, LK11, showed cyclic ability with repeat reactions over twenty cycles. Thus, LK11 pellet can be used as a thermochemical storage material because of its ability to store and release heat at high temperatures, ranging from 550 to $700^{\circ} \mathrm{C}$.
\end{abstract}

\section{Introduction}

Thermal energy storage is a significant and viable solution to counter serious environmental issues, including global warming and natural source depletion. Thermal energy storage is a technology which is designed to accumulate energy when production exceeds demand, and to make it available at the users' demand. Among thermal energy storage technologies, the thermochemical energy storage (TcES) system is considered to be the most promising, offering several advantages, such as relatively low energy loss during long-term storage and high thermal energy storage density.

At the high temperature of $700^{\circ} \mathrm{C}$, the lithium orthosilicate/ carbon dioxide $\left(\mathrm{LiSiO}_{4} / \mathrm{CO}_{2}\right)$ reaction is one candidate of thermochemical energy storages (Takasu et al., 2017). Deployment of this system is considered an appropriate method to enhance the utilization of surplus or waste heat from high temperature industrial processes such as in the ironmaking industry (Maruoka et al., 2004; Zhang et al., 2013; Shigaki et al., 2015), solar power plants (Ervin, 1977; Tian and Zhao, 2013; Carrillo et al., 2019), high-temperature gas-cooled reactors, etc. (Kato et al., 2001; Okazaki et al., 2015; Forsberg et al., 2018).

Thermochemical storage systems based on $\mathrm{LiSiO}_{4} / \mathrm{CO}_{2}$ uses the reversible chemical reaction and sorption to change the temperature level of thermal energy stored by chemical

Received on May 29, 2020; accepted on September 16, 2020 DOI: $10.1252 /$ jcej.20we097

Correspondence concerning this article should be addressed to $\mathrm{H}$. Takasu (E-mail address: takasu.h.aa@m.titech.ac.jp). substances. It is based on the following equilibria:

$$
\mathrm{Li}_{4} \mathrm{SiO}_{4}(\mathrm{~s})+\mathrm{CO}_{2}(\mathrm{~g}) \rightleftarrows \mathrm{Li}_{2} \mathrm{CO}_{3}(\mathrm{~s})+\mathrm{Li}_{2} \mathrm{SiO}_{3}(\mathrm{~s})
$$

$\mathrm{Li}_{4} \mathrm{SiO}_{4}$ can absorb the same amount of $\mathrm{CO}_{2}$ and produces lithium carbonate $\left(\mathrm{Li}_{2} \mathrm{CO}_{3}\right)$ and lithium metasilicate $\left(\mathrm{Li}_{2} \mathrm{SiO}_{3}\right)$, and the reaction enthalpy, $\Delta H_{\mathrm{r}}$, is around $-94 \mathrm{~kJ} \mathrm{~mol}^{-1}$ (Barin, 1995). Even though other metal oxides can react with $\mathrm{CO}_{2}$ at high temperatures (Kyaw et al., 1996; Kato et al., 1999; Cot-Gores et al., 2012), the reactivity of $\mathrm{Li}_{4} \mathrm{SiO}_{4}$ is relatively high. In our earlier research work, $\mathrm{Li}_{4} \mathrm{SiO}_{4}$ was confirmed to have sufficient performance as a TcES material at $700^{\circ} \mathrm{C}$ (Takasu et al., 2017, 2018). However, the reactivity of $\mathrm{Li}_{4} \mathrm{SiO}_{4}$ was decreased dramatically at temperatures lower than $680^{\circ} \mathrm{C}$. This is caused by the melting temperature of $\mathrm{Li}_{2} \mathrm{CO}_{3}\left(723^{\circ} \mathrm{C}\right)$. Formation of solid $\mathrm{Li}_{2} \mathrm{CO}_{3}$ and $\mathrm{Li}_{2} \mathrm{SiO}_{3}$ layers on the unreacted $\mathrm{Li}_{4} \mathrm{SiO}_{4}$ disturb the $\mathrm{CO}_{2}$ diffusion and inhibit further reaction. Considering the application for high temperature TcES, reactivity improvement of $\mathrm{Li}_{4} \mathrm{SiO}_{4}$ is required at especially low temperatures.

The alkali metal carbonates such as potassium carbonates $\left(\mathrm{K}_{2} \mathrm{CO}_{3}\right)$ and sodium carbonates $\left(\mathrm{Na}_{2} \mathrm{CO}_{3}\right)$ are well-known additives that improve the $\mathrm{CO}_{2}$ sorption property of $\mathrm{Li}_{4} \mathrm{SiO}_{4}$ (Yan et al., 2019). For instance, Seggiani et al. (2013) reported the sorption performance of $\mathrm{Li}_{4} \mathrm{SiO}_{4}$ with different ratios (10-30 mass $\%$ ) of $\mathrm{K}_{2} \mathrm{CO}_{3}$ and $\mathrm{Na}_{2} \mathrm{CO}_{3}$, under $4 \% \mathrm{CO}_{2}$ concentration at $580^{\circ} \mathrm{C}$ and the sample with 30 mass $\%$ of $\mathrm{K}_{2} \mathrm{CO}_{3}$ exhibited higher sorption capacity and durability than pure $\mathrm{Li}_{4} \mathrm{SiO}_{4}$ (Yan et al., 2019). Yan et al. (2019) also investigated the sorption performance of $\mathrm{Li}_{4} \mathrm{SiO}_{4}$, using a small mix (1-10 mass $\%$ and 5-20 mass $\%$ ) of $\mathrm{K}_{2} \mathrm{CO}_{3}$ and $\mathrm{Na}_{2} \mathrm{CO}_{3}$ under 
Table 1 Summary information of prepared pellets

\begin{tabular}{|c|c|c|c|c|c|c|c|c|}
\hline \multirow{2}{*}{ Sample } & \multirow{2}{*}{$\begin{array}{c}\text { Molar ratio of } \\
\mathrm{Li}_{2} \mathrm{CO}_{3}: \mathrm{SiO}_{2}: \mathrm{K}_{2} \mathrm{CO}_{3}\end{array}$} & \multicolumn{3}{|c|}{ Mass ratio* [mass\%] } & \multirow{2}{*}{ Height [mm] } & \multirow{2}{*}{ Diameter [mm] } & \multirow{2}{*}{$\begin{array}{l}\text { Initial pellet } \\
\text { mass [mg] }\end{array}$} & \multirow{2}{*}{$\begin{array}{c}\text { Pellet mass, } m_{\text {pellet }} \\
\text { (after pre-treatment) } \\
{[\mathrm{mg}]}\end{array}$} \\
\hline & & $\mathrm{K}_{2} \mathrm{O} \cdot 8 \mathrm{TiO}_{2}$ & $\mathrm{CMC}$ & $\mathrm{H}_{2} \mathrm{O}$ & & & & \\
\hline LK0 & $2.0: 1.1: 0$ & 10 & 5 & 20 & $4.8 \pm 0.3$ & $7.1 \pm 0.1$ & $229 \pm 8$ & $134 \pm 2$ \\
\hline LK6 & $2.0: 1.1: 0.06$ & 10 & 5 & 20 & $4.6 \pm 0.3$ & $7.1 \pm 0.1$ & $230 \pm 11$ & $134 \pm 4$ \\
\hline LK11 & $2.0: 1.1: 0.11$ & 10 & 5 & 20 & $4.5 \pm 0.3$ & $7.1 \pm 0.1$ & $238 \pm 5$ & $134 \pm 3$ \\
\hline LK17 & $2.0: 1.1: 0.17$ & 10 & 5 & 20 & $4.3 \pm 0.2$ & $7.1 \pm 0.1$ & $235 \pm 6$ & $134 \pm 2$ \\
\hline LK33 & $2.0: 1.1: 0.33$ & 10 & 5 & 20 & $4.0 \pm 0.2$ & $7.1 \pm 0.1$ & $238 \pm 4$ & $135 \pm 5$ \\
\hline
\end{tabular}

* Mass ratio to the total mass of $\mathrm{Li}_{2} \mathrm{CO}_{3}$ and $\mathrm{SiO}_{2}$ in the mixture

$15 \%$ of $\mathrm{CO}_{2}$ at $550^{\circ} \mathrm{C}$. It was confirmed that both additives enhanced reaction rates and capacities of $\mathrm{Li}_{4} \mathrm{SiO}_{4}$, and the sample with 5 mass $\%$ of $\mathrm{K}_{2} \mathrm{CO}_{3}$ and 10 mass\% of $\mathrm{Na}_{2} \mathrm{CO}_{3}$ were the optimum addition ratios under the measurement conditions. Although they confirmed the reactivity enhancement with the alkali metal carbonates, the optimum additive ratio is likely to change depending on the measurement conditions.

Especially for its utilization as a high temperature TcES, reactivities of $\mathrm{Li}_{4} \mathrm{SiO}_{4}$ under high concentrations of $\mathrm{CO}_{2}$ needs be investigated. In our previous work, the reactivity enhancement of $\mathrm{K}_{2} \mathrm{CO}_{3}$ was also confirmed with $\mathrm{Li}_{4} \mathrm{SiO}_{4}$ pellets at $600-700^{\circ} \mathrm{C}$ (Kim et al., 2019a, 2019b). However, the reactivities of $\mathrm{Li}_{4} \mathrm{SiO}_{4}$ with different ratios of $\mathrm{K}_{2} \mathrm{CO}_{3}$ additives had not been completed under high concentrations of $\mathrm{CO}_{2}$. Therefore, in this study, $\mathrm{Li}_{4} \mathrm{SiO}_{4}$ tablets with different ratios of $\mathrm{K}_{2} \mathrm{CO}_{3}$ additives were prepared and the reactivities of these pellets were compared between $550-700^{\circ} \mathrm{C}$. Also, the durability of a $\mathrm{Li}_{4} \mathrm{SiO}_{4}$ pellet was investigated at $600^{\circ} \mathrm{C}$ for 20 cycles.

\section{Experimental}

\subsection{Material}

Initially, the initial materials of lithium carbonate ( $\mathrm{Li}_{2} \mathrm{CO}_{3}, 99.0 \%$, Wako Pure Chemical Industries, Ltd.), silicon dioxide $\left(\mathrm{SiO}_{2}, 99.0 \%\right.$, Wako Pure Chemical Industries, Ltd.), and potassium carbonate $\left(\mathrm{K}_{2} \mathrm{CO}_{3}, 99.0 \%\right.$, Wako Pure Chemical Industries, Ltd.) were mixed with mortar and pestle. The mixing molar ratios of $\mathrm{Li}_{2} \mathrm{CO}_{3} / \mathrm{SiO}_{2} / \mathrm{K}_{2} \mathrm{CO}_{3}$ were $2.0: 1.1: 0,0.06,0.11,0.17$, and 0.33 .

Next, potassium titanate fiber $\left(\mathrm{K}_{2} \mathrm{O} \cdot 8 \mathrm{TiO}_{2}\right.$, TISMO-D, Otsuka Chemical Co., Ltd.), carboxymethyl cellulose (CMC, CMF-7, AS ONE), and pure water were added to the mixture as a reinforcing agent and a granulation binder, and it was also mixed with a mortar and pestle. The additive amounts of potassium titanate fiber, CMC and water were $1 / 10,1 / 20$, and $1 / 5$ as much as the total mass of $\mathrm{Li}_{2} \mathrm{CO}_{3}$ and $\mathrm{SiO}_{2}$ in the mixture. Around $250 \mathrm{mg}$ of powder was put into a mold $(\phi: 7.0 \mathrm{~mm})$ and compressed with $15 \mathrm{kN}$ for $3 \mathrm{~min}$ by a table press (TB-20H, Sansho Industry Co., Ltd.). Finally, lithium silicate pellets were obtained. According to the ratio of $\mathrm{K}_{2} \mathrm{CO}_{3}$, each pellet was named LK0, LK6, LK11, LK17 and LK33, and the basic information of these pellets is summarized in Table 1.

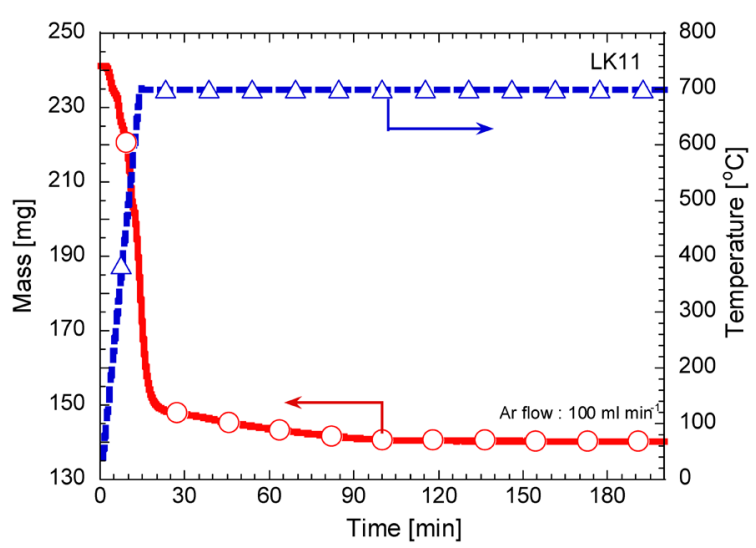

Fig. 1 Mass change of LK11 under thermal treatment under Ar flow

\subsection{Pre-treatment}

All pellets were subjected to thermal treatment to synthesize lithium orthosilicate and remove residues, as pretreatment. A pellet was heated up to $700^{\circ} \mathrm{C}$ from room temperature under Argon (Ar) flow, and was kept for $90 \mathrm{~min}$ at $700^{\circ} \mathrm{C}$. Figure 1 shows the mass change of LK11 during thermal treatment. Initially, a rapid mass drop was observed with increasing temperature. Hereafter, a modest decline was observed for around $90 \mathrm{~min}$ after reaching $700^{\circ} \mathrm{C}$. Afterward, almost no change was observed. Similar behavior was observed for all pellets. These results confirmed that thermal treatment at $700^{\circ} \mathrm{C}$ for $90 \mathrm{~min}$ was suitable as a pre-treatment for these silicate pellets. The mass of the pellet after pretreatment, $m_{\text {pellet }}$, was measured and summarized in Table 1.

\subsection{Reactivity measurement}

After pre-treatment, reactivity measurement for carbonation and decarbonation was conducted at 4 different temperatures $\left(550,600,650\right.$, and $\left.700^{\circ} \mathrm{C}\right)$, using a thermobalance (TG-9600S; Ulvac Shinku-Riko Inc.). For taking this measurement, the thermobalance was kept at the target temperature for $360 \mathrm{~min}$. For carbonation and decarbonation, $100 \mathrm{~mL} \mathrm{~min}^{-1}$ (STP) of $\mathrm{CO}_{2}$ and Ar were supplied to the pellet for $180 \mathrm{~min}$. Mass changes of pellet were measured by the thermobalance, and the reacted $\mathrm{CO}_{2}$ amount, $n_{\mathrm{CO}_{2}}\left[\mathrm{~mol} / \mathrm{kg}_{\text {pellet }}\right]$, was calculated as in Eq. (2).

$$
n_{\mathrm{CO}_{2}}=\frac{\Delta m}{M_{\mathrm{CO}_{2}} \cdot m_{\text {pellet }}}
$$

Herein, $\Delta m[\mathrm{~kg}], M_{\mathrm{CO}_{2}}[\mathrm{~kg} / \mathrm{mol}]$, and $m_{\text {pellet }}[\mathrm{kg}]$ indicate the 
mass change, the molar mass of $\mathrm{CO}_{2}$, and mass of the pellet, respectively.

\subsection{Durability measurement}

After pre-treatment, durability measurement was conducted with $\mathrm{LK} 11$ at $600^{\circ} \mathrm{C}$ for 20 cycles. For carbonation and decarbonation, $100 \mathrm{~mL} \mathrm{~min}^{-1}(\mathrm{STP})$ of $\mathrm{CO}_{2}$ and $\mathrm{Ar}$ was supplied to the pellet each for $90 \mathrm{~min}$. The thermal output and storage density, $q_{\text {output }}, q_{\text {storage }}\left[\mathrm{kJ} / \mathrm{kg}_{\text {pellet }}\right]$, were calculated from the $\mathrm{CO}_{2}$ amount absorbed and desorbed, respectively, as shown in Eq. (3).

$$
q_{\text {output, storage }}=-\Delta H_{r} \cdot \Delta n_{\text {carb, decarb }}
$$

Herein, $\Delta n_{\text {carb, decarb }}$ indicates the change of the reacted $\mathrm{CO}_{2}$ amount for each carbonation and decarbonation process, and is defined as shown in Eqs. (4), (5).

$$
\begin{aligned}
& \Delta n_{\text {carb }}=n_{\text {carb,f }}-n_{\text {carb,i }} \\
& \Delta n_{\text {decarb }}=n_{\text {decarb,i },}-n_{\text {decarb }, \mathrm{f}}
\end{aligned}
$$

Herein, $n_{\text {carb, },}, n_{\text {cdearb, }}, n_{\text {carb, } \mathrm{f}}$ and $n_{\text {decarb, }}$ refer to values of $n$ at the beginning and the end of the carbonation and decarbonation processes.

\section{Results and Discussion}

The changes in the reacted $\mathrm{CO}_{2}$ amount resulting from the carbonation and decarbonation processes for LK0, LK6, 11,17 and 33 pellets measured at 550,600,650 and $700^{\circ} \mathrm{C}$ are presented in Figure 2. During carbonation, LK6, LK11, and LK17 showed large changes in terms of the reacted $\mathrm{CO}_{2}$ amount, compared to the LK0 pellet, which indicates that the $\mathrm{K}_{2} \mathrm{CO}_{3}$ additive in LK6, 11, and 17 was employed for reactivity enhancement. In other words, the $\mathrm{K}_{2} \mathrm{CO}_{3}$ additive plays a significant role in producing a eutectic salt with $\mathrm{Li}_{2} \mathrm{CO}_{3}$, which is covered with unreacted $\mathrm{Li}_{4} \mathrm{SiO}_{4}$ during carbonation. As a consequence, the melting point becomes lower than that of pure $\mathrm{Li}_{2} \mathrm{CO}_{3}$, thereby accelerating $\mathrm{CO}_{2}$ diffusion through this eutectic liquid. As a result, carbonation reactivity is enhanced. However, LK33 showed inferior performance when compared with LK6, LK11, and LK17 at all temperatures. This result implies that excessive $\mathrm{K}_{2} \mathrm{CO}_{3}$ additives impede the reactivity of $\mathrm{Li}_{4} \mathrm{SiO}_{4}$.

In decarbonation, all pellets desorbed over $90 \%$ of $\mathrm{CO}_{2}$, which were absorbed in carbonation at 700 and $650^{\circ} \mathrm{C}$, as shown in Figure 2(a) and (b). Considering the reactivity at different temperatures, a trend was observed in the pellets with less $\mathrm{K}_{2} \mathrm{CO}_{3}$ additive. A large change of the reacted $\mathrm{CO}_{2}$ amount was observed at 650,600 and $550^{\circ} \mathrm{C}$, at different temperatures, a trend was observed in the pellets with less $\mathrm{K}_{2} \mathrm{CO}_{3}$ additive. A large change of the reacted $\mathrm{CO}_{2}$ amount was observed at 650,600 and $550^{\circ} \mathrm{C}$, as shown in Figure 2(b)-(d). In addition, LK33 was confirmed to perform below par during decarbonation, as compared to other pellets at 650, 600 and $550^{\circ} \mathrm{C}$. According to a phase-diagram of $\mathrm{K}_{2} \mathrm{CO}_{3}-\mathrm{Li}_{2} \mathrm{CO}_{3}$ (CRCT-ThermoFact.inc and GTT-Technologies, 2018), the melting temperature of salt liquid tends to increase rap-
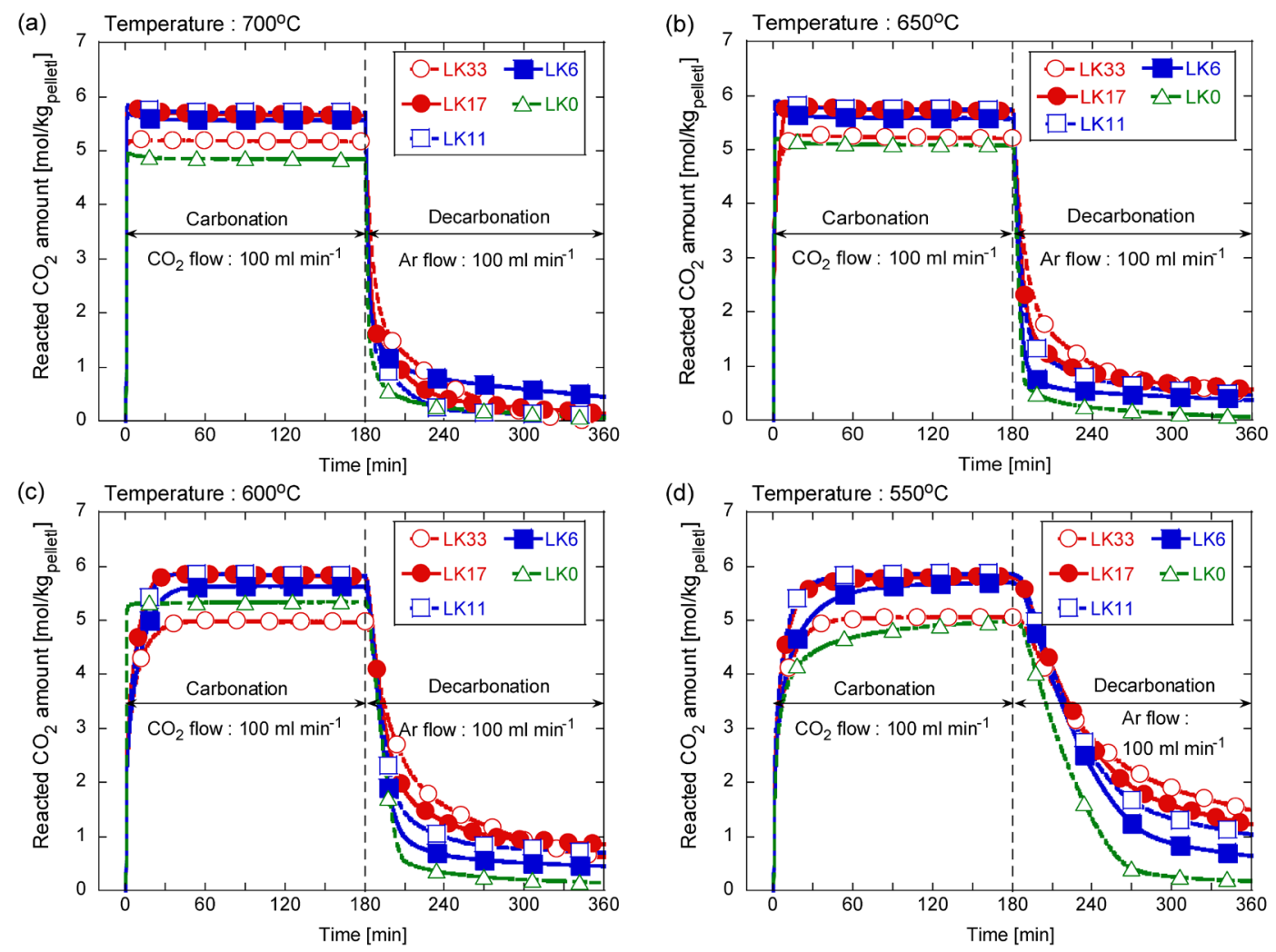

Fig. 2 Carbonation and decarbonation behavior of LK samples at (a) 700, (b) 650, (c) 600, and (d) $550^{\circ} \mathrm{C}$ under $100 \mathrm{kPa}$ of $\mathrm{CO}_{2}$; carbonation process: $100 \mathrm{~mL} \mathrm{~min}^{-1}$ of $\mathrm{CO}_{2}$ flow for $180 \mathrm{~min}$; decarbonation process: $100 \mathrm{~mL} \mathrm{~min}^{-1}$ of Ar flow for $180 \mathrm{~min}$ 
idly corresponding to increasing ratio of $\mathrm{K}_{2} \mathrm{CO}_{3}$. Thus, excess $\mathrm{K}_{2} \mathrm{CO}_{3}$ seemingly remains as solid state in the pellets and it may disturb reactions especially at low temperature.

These results indicated that proper amounts of $\mathrm{K}_{2} \mathrm{CO}_{3}$ additive can enhance carbonation. Also, excessive $\mathrm{K}_{2} \mathrm{CO}_{3}$ can impede the reactivity of carbonation, as well as decarbonation, especially at low temperatures.

To further investigate the effects of the concentration of $\mathrm{K}_{2} \mathrm{CO}_{3}$ additive, the change in the reacted $\mathrm{CO}_{2}$ amount in $60 \mathrm{~min}$ for carbonation and decarbonation processes of LK pellets were evaluated and shown in Figure 3.

As shown in Figure 3(a), it was found that the change in the reacted $\mathrm{CO}_{2}$ amount in carbonation, $\Delta n_{\text {carb }}$, initially increased with increasing concentrations of $\mathrm{K}_{2} \mathrm{CO}_{3}$ additive. It reached its maximum value at LK11 and LK17, and then decreased again regardless of the carbonation temperature. The maximum value of $\Delta n_{\text {carb }}$ was attained by the LK11 pellet, including $11 \mathrm{~mol} \%$ of $\mathrm{K}_{2} \mathrm{CO}_{3}$ additive to $\mathrm{Li}_{4} \mathrm{SiO}_{4}$. For instance, LK11 pellet showed $\Delta n_{\text {carb }}$ of $5.73,5.76,5.86$, and $5.84 \mathrm{~mol} \mathrm{~kg}_{\text {pellet }}{ }^{-1}$, at $700,650,600$ and $550^{\circ} \mathrm{C}$, respectively.

Figure 3(b) shows the change in the reacted $\mathrm{CO}_{2}$ amount in decarbonation, $\Delta n_{\text {decarb }}$, of LK pellets, calculated based on the decarbonation data at $700,650,600$, and $550^{\circ} \mathrm{C}$, for the first $60 \mathrm{~min}$ of decarbonation. As observed from the com- parison figure, two different trends were seen, depending on the decarbonation temperature. At lower temperature ranges $\left(550-600^{\circ} \mathrm{C}\right)$, the heat storage density kept decreasing when the concentration of $\mathrm{K}_{2} \mathrm{CO}_{3}$ additive varied between 0 and 33. Conversely, at higher temperature ranges $\left(650-700^{\circ} \mathrm{C}\right)$, the $\Delta n_{\text {decarb }}$ initially increased with the increase in the concentration of $\mathrm{K}_{2} \mathrm{CO}_{3}$ additive, after which, it reached the maximum value. Hereafter, it started decreasing again. At temperature of $650^{\circ} \mathrm{C}$, a maximum value of $5.05 \mathrm{~mol} \mathrm{~kg}_{\text {pellet }}{ }^{-1}$ was recorded for the LK6 pellet, having $6 \mathrm{~mol} \%$ of $\mathrm{K}_{2} \mathrm{CO}_{3}$ additive. When the temperature was increased from 650 to $700^{\circ} \mathrm{C}$, the maximum value shifted, and a $5.49 \mathrm{~mol} \mathrm{~kg}_{\text {pellet }}{ }^{-1}$ of $\Delta n_{\text {decarb }}$ was found for the LK11 pellet, possessing $11 \mathrm{~mol} \%$ of the $\mathrm{K}_{2} \mathrm{CO}_{3}$ additive to $\mathrm{Li}_{4} \mathrm{SiO}_{4}$.

On the basis of the results derived from the changed $\mathrm{CO}_{2}$ amount of LK pellets, 11 mol\% concentration of $\mathrm{K}_{2} \mathrm{CO}_{3}$ additive would be the optimum value to fabricate high performance storage materials.

The cycle ability of the LK11 pellet (including $11 \mathrm{~mol} \%$ concentration of $\mathrm{K}_{2} \mathrm{CO}_{3}$ additive) was explored, and the results are shown in Figure 4.

The carbonation and decarbonation behaviors measured at $600^{\circ} \mathrm{C}$ are shown in Figure 4(a). It was observed that carbonation and decarbonation occurred for each cycle, and
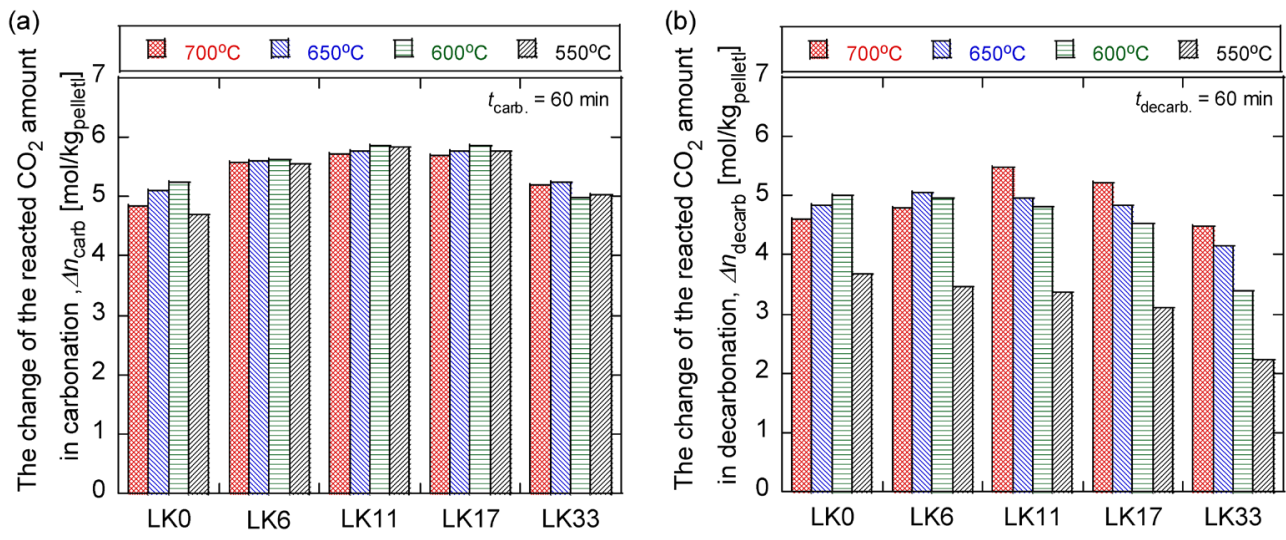

Fig. 3 Dependency of $\mathrm{K}_{2} \mathrm{CO}_{3}$ additive on the change of the reacted $\mathrm{CO}_{2}$ amount for (a) carbonation and (b) decarbonation process of LK samples for $60 \mathrm{~min}$ at $700,650,600$, and $550^{\circ} \mathrm{C}$

(a)

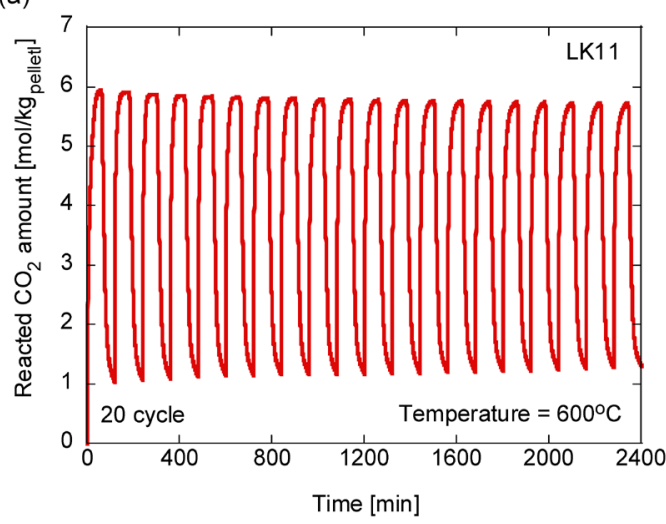

(b)

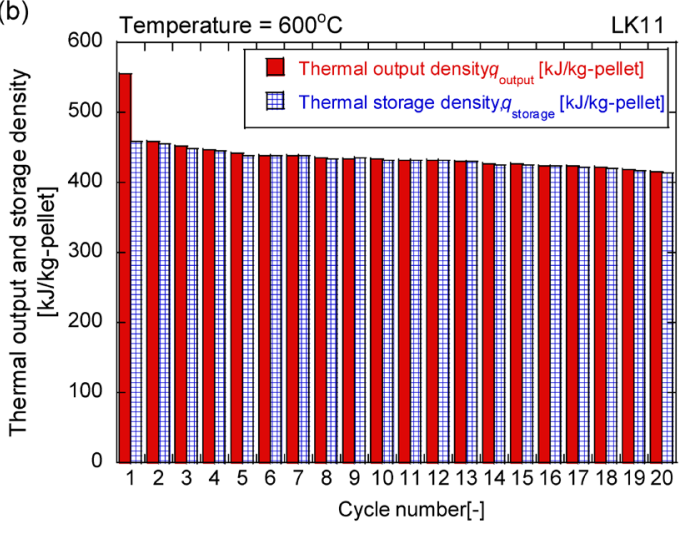

Fig. 4 (a) The reacted $\mathrm{CO}_{2}$ amount and (b) thermal output and storage density of LK11 on the 20-cycle experiment at $600^{\circ} \mathrm{C}$; carbonation process: $100 \mathrm{~mL} \mathrm{~min}^{-1}$ of $\mathrm{CO}_{2}$ flow for $90 \mathrm{~min}$; decarbonation process: $100 \mathrm{~mL} \mathrm{~min}^{-1}$ of Ar flow for $90 \mathrm{~min}$ 

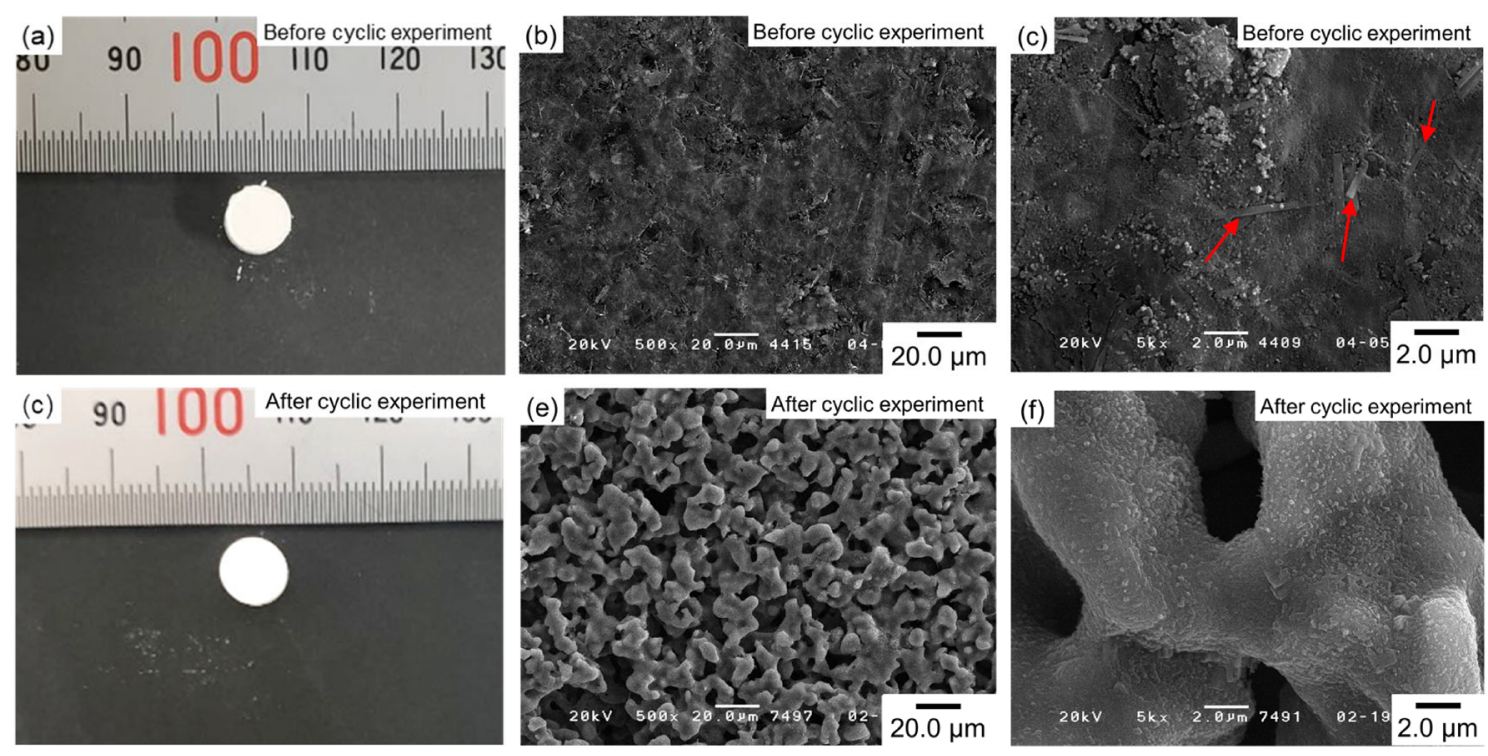

Fig. 5 Images of top pellet surface and SEM images of LK11 $(a-c)$ before and $(c-f)$ after cycle experiment

no significant decrease in reactivity was found during 20 cyclic experiments. Therefore, thermal output and storage densities, $q_{\text {output }}$ and $q_{\text {storage }}$, were determined for each cycle, as shown in Figure 4(a). The results are presented in Figure 4(b). It was found that the value of $q_{\text {output }}$ storage exceeded $550 \mathrm{~kJ} \mathrm{~kg}^{-1}$ in the first cycle. Then, it decreased slightly between the 2 nd and 20th cycles.

The reduction in carbonation and decarbonation processes was less than approximately $11 \%$. On the 20 th cycle, the LK11 pellet showed $q_{\text {output }}$ and $q_{\text {storage }}$ of both $410 \mathrm{~kJ} \mathrm{~kg}$ pellet. This result showed that the LK11 pellet was able to withstand repetitive cyclic reactions without significant failures.

Figure 5(a) and (c) gives the images of the top pellet surfaces, and SEM images of LK11 before and after the cyclic experiment. As illustrated in Figure 5(a) and (c), no significant difference, such as cracks or structural changes, were observed. In addition, the height and diameter of LK11 after the cycle experiment were 4.5 and $7.2 \mathrm{~mm}$, respectively, and thus, no volume change was observed. As a consequence, further characterization on the surfaces of LK11 were done by using the scanning electron microscope (SEM). Figure 5(b), (c), (e), and (f) presents images of SEM at magnifications of $\times 500$ and $5 \mathrm{k}$, respectively, before and after the cyclic experiment. As presented in Figure 5(b) and (c), fresh LK11 pellet showed a dense structure, with the presence of some potassium titanate fibers, which could be seen particularly at high magnification of $\times 5 \mathrm{k}$, indicated by the arrow in the figure. On the other hand, the morphology was changed from dense to porous after the cyclic experiment. The potassium titanate fiber was not observed on the surface of the used pellet, as shown in Figure 5(e) and (f). It is assumed that the repetitive liquefaction and solidification of the eutectic salt caused the microstructure change, owing to $\mathrm{CO}_{2}$ diffusion. To add to that, the tubular fillers also lead to the development the porous structure.

\section{Conclusions}

In this study, the effects of the concentration of the $\mathrm{K}_{2} \mathrm{CO}_{3}$ additive on carbonation and decarbonation behaviors were investigated using the thermogravimetric approach, and the experimental results were discussed. The pellets with five different concentrations of $\mathrm{K}_{2} \mathrm{CO}_{3}$ additive $(0,6,11,17$ and $33 \mathrm{~mol} \%$ ) were investigated. A $11 \mathrm{~mol} \%$ concentration of $\mathrm{K}_{2} \mathrm{CO}_{3}$ additive would be the optimum value to fabricate high performance storage materials, based on the results derived from the carbonation and decarbonation experiments. The $\Delta n_{\text {carb }}$ values of LK11 were $5.73,5.76,5.86$, and $5.84 \mathrm{~mol} \mathrm{~kg}_{\text {pellet }}{ }^{-1}$ at $700,650,600$ and $550^{\circ} \mathrm{C}$, respectively. As for the cycle experiment, LK11 showed repetitive cyclic durability without significant failures, with less than $11 \%$ of degradation between the 2nd and 20th cycle. On the 20th cycle, the LK11 pellet showed a similar $q_{\text {output }}$ and $q_{\text {storage }}$ as the $410 \mathrm{~kJ} \mathrm{~kg}_{\text {pellet. }}$ After the cyclic experiment, the LK11 pellet maintained the macrostructure and no significant change on the surface was found. According to the SEM characterization, the fresh pellet had a dense morphology. However, it became porous after the cyclic experiment. Therefore, the LK11 pellet showed superior performance, and is a promising candidate for thermochemical energy storage at high temperatures above $600^{\circ} \mathrm{C}$.

\section{Literature Cited}

Barin, I.; Thermochemical Data of Pure Substances 3rd ed., pp. 404-985, VCH Publishers, Inc., Weinheim, U.S.A. (1995)

Carrillo, A. J., J. González-Aguilar, M. Romero and J. M. Coronado; "A Review on High Temperature Thermochemical Heat Storage Systems and Materials," Chem. Rev., 119, 4777-4816 (2019)

Cot-Gores, J., A. Castell and L. F. Cabeza; "Thermochemical Energy Storage and Conversion: A-State-of-the-Art Review of the Experimental Research under Practical Conditions," Renew. Sustain. Energy Rev., 16, 5207-5224 (2012) 
CRCT-ThermoFact.inc and GTT-Technologies; FactSage 7.2, www.fact sage.com (2018)

Ervin, G.; "Solar Heat Storage Using Chemical Reactions," J. Solid State Chem., 22, 51-61 (1977)

Forsberg, C., S. Brick and G. Haratyk; "Coupling Heat Storage to Nuclear Reactors for Variable Electricity Output with Baseload Reactor Operation," Electr. J., 31, 23-31 (2018)

Kato, Y., N. Harada and Y. Yoshizawa; "Kinetic Feasibility of a Chemical Heat Pump for Heat Utilization of High-Temperature Processes," Appl. Therm. Eng., 19, 239-254 (1999)

Kato, Y., M. Yamada, T. Kanie and Y. Yoshizawa; "Calcium Oxide/ Carbon Dioxide Reactivity in a Packed Bed Reactor of a Chemical Heat Pump for High-Temperature Gas Reactors," Nucl. Eng. Des., 210, 1-8 (2001)

Kim, S. T., C. Kurahashi, H. Hoshino, C. Takahashi, Y. Tamura, H. Takasu, S. Saito, M. Kurihara and Y. Kato; "Thermal Driving Demonstration of $\mathrm{Li}_{4} \mathrm{SiO}_{4} / \mathrm{CO}_{2} /$ Zeolite Thermochemical Energy Storage System for Efficient High-Temperature Heat Utilizations," ISIJ Int., 59, 721-726 (2019a)

Kim, S. T., T. Nihei, C. Kurahashi, H. Hoshino, H. Takasu and Y. Kato; "Kinetic Study of Lithium Orthosilicate Pellets for High-Temperature Chemical Heat Pumps," Energy Storage, 1, 1-9 (2019b)

Kyaw, K., M. Kanamori, H. Matsuda and M. Hasatani; "Study of Carbonation Reactions of Ca-Mg Oxides for High Temperature Energy Storage and Heat Transformation," J. Chem. Eng. Japan, 29, 112-118 (1996)

Maruoka, N., T. Mizuochi, H. Purwanto and T. Akiyama; "Feasibil- ity Study for Recovering Waste Heat in the Steelmaking Industry Using a Chemical Recuperator," ISIJ Int., 44, 257-262 (2004)

Okazaki, T., Y. Shirai and T. Nakamura; "Concept Study of Wind Power Utilizing Direct Thermal Energy Conversion and Thermal Energy Storage," Renew. Energy, 83, 332-338 (2015)

Seggiani, M., M. Puccini and S. Vitolo; "Alkali Promoted Lithium Orthosilicate for $\mathrm{CO}_{2}$ Capture at high Temperature and Low Concentration," Int. J. Greenh. Gas Control, 17, 25-31 (2013)

Shigaki, N., H. Tobo, S. Ozawa, Y. Ta and K. Hagiwara; "Heat Recovery Process from Packed Bed of Hot Slag Plates," ISIJ Int., 55, 2258-2265 (2015)

Takasu, H., J. Ryu and Y. Kato; "Application of Lithium Orthosilicate for High-Temperature Thermochemical Energy Storage," Appl. Energy, 193, 74-83 (2017)

Takasu, H., S. Funayama, N. Uchiyama, H. Hoshino, Y. Tamura and Y. Kato; "Kinetic Analysis of the Carbonation of Lithium Orthosilicate Using the Shrinking Core Model," Ceram. Int., 44, 11835-11839 (2018)

Tian, Y. and C. Y. Zhao; "A Review of Solar Collectors and Thermal Energy Storage in Solar Thermal Applications," Appl. Energy, 104, 538-553 (2013)

Yan, X., Y. Li, X. Ma, J. Zhao and Z. Wang; "Performance of $\mathrm{Li}_{4} \mathrm{SiO}_{4} \mathrm{Ma}-$ terial for $\mathrm{CO}_{2}$ Capture: A Review," Int. J. Mol. Sci., 20, 928 (2019)

Zhang, H., H. Wang, X. Zhu, Y. J. Qiu, K. Li, R. Chen and Q. Liao; "A Review of Waste Heat Recovery Technologies towards Molten Slag in Steel Industry," Appl. Energy, 112, 956-966 (2013) 